\title{
O GRANDE SILÊNCIO: INVISIBILIDADE E TRANSFEMINICÍDIO NO BRASIL
}

\author{
Iohana do Nascimento Corrêa Berto
}

\begin{abstract}
"Então temos que nos perguntar: por que alguém é morto pelo jeito que anda? Por que esse jeito de andar é tão perturbador para os outros meninos que eles sentiram que deveriam negar essa pessoa? Eles apagariam os vestígios desta pessoa, eles deveriam parar aquele andar de qualquer jeito. Eles devem ter se sentido obrigados a erradicar a possibilidade daquela pessoa andar novamente. Parece, para mim, que nós estamos falando de um extremo e profundo pânico ou medo, uma ansiedade que está presa às normas de gênero. É como se alguém dissesse: "você deve respeitar as normas da masculinidade, pois, caso contrário, você morrerá, ou mato você agora porque você não respeita!". Então nós temos que começar a nos questionar qual a relação entre se submeter e se adequar às normas de gênero." (Judith Butler)
\end{abstract}

\section{OBJETIVOS}

Este estudo tem como objetivo central analisar as dificuldades e vulnerabilidades em que se encontram as pessoas trans no Brasil: viver no país com o maior índice de transfeminicídio do mundo, segundo fontes das Nações Unidas; como também, provocar reflexões sobre a invisibilidade trans nos diferentes segmentos sociais que envolvem a (auto)definição; do processo de "tornar-se" mulher e o aniquilamento da identidade socialmente construída através da transcendência por uma sociedade que se mostra cada vez mais conservadora e heteronormativa em sua essência; aniquilamento que se dá ao retirar a transexualidade e a travestilidade das esferas sociais, com exclusões, discursos de ódio, agressões físicas e chegando ao extremo da intolerância, a violação do direito à vida.

\section{JUSTIFICATIVA}

De acordo com a ONG Internacional Transgender Europe, fato também revelado pelo Conselho de Segurança das Nações Unidas (2015), o Brasil é o país mais perigoso do mundo de se viver para a população trans (travestis, transexuais e transgêneros), pois esse segmento é dizimado diariamente em função da violência de gênero. Essa realidade se evidencia por notícias que chegam todos os dias de que travestis e transexuais são violentamente agredidas, torturadas e assassinadas por motivos de desprezo e intolerância.

Para não generalizar os crimes cometidos contra os LGBTTT, a fim de produzir um estudo honesto e direcionado a população trans, será usado o termo 'transfeminicídio', que provém de 'feminicídio', reconhecido como lei no Brasil desde 2015, caracterizado pela 
cultura e incidência sistemática de assassinatos de mulheres por motivos de repugnância. Logo, considerando o termo "mulher" como um gênero socialmente construído, em que "tornar-se mulher" é uma construção de identidade e sexo refere-se apenas ao órgão biológico de nascimento, o que não define o "ser político e social", é através da transcendência de corpos e identidades que é possível considerar que o termo 'feminicídio' se adequa confortavelmente a todas as formas de feminilidades (BEAUVOIR, 1980; BENTO, 2014; BUTLER, 2008).

No Brasil, o aniquilamento trans configura um total de $50 \%$ de assassinatos a essa população cometidos em todo o mundo, segundo o Internacional Transgender Europe e o Grupo Gay da Bahia. Em 2014 (dados mais atualizados), foram documentados 134 assassinatos de travestis e transexuais, segundo professor Luiz Mott (2014). Mas é de grande relevância pensar que esta estatística pode ser ainda maior, visto que, tais dados são elaborados através de denúncias e pesquisas feitas por ativistas e grupos LGBTTT, sendo que, em uma parcela considerável, as vítimas se sentem coagidas a não denunciarem as agressões e em casos de assassinatos, as famílias não o fazem por se sentirem "constrangidas" em revelar as identidades de seus entes. Sérgio Carrara (2006) defende que atos criminosos cometidos em função do gênero, em suas diversas formas de expressões, que rompem o paradigma entre sexo e identidade, são consideravelmente maiores que as violações cometidas em razão da orientação sexual. Ou seja, a identidade trans em sua natureza é mais vulnerável aos crimes de ódio, que configura o quadro de 'transfobia' (CARRARA, 2006; MOTT, 2014).

É preciso levar em consideração também, a omissão do Estado em fornecer fontes oficiais e confiáveis sobre crimes em razão da orientação sexual e identidade de gênero. Da mesma forma, a falta de elaboração de políticas públicas e de leis mais específicas para esses crimes tornam a invisibilidade e o aniquilamento dessa população maior. Portanto, ser transexual ou travesti no Brasil é correr grande risco de ser violentada, assassinada e excluída de serviços básicos prestados à população, inclusive, saúde pública. Visto que, em uma pesquisa elaborada pela UNAIDS, a nível mundial, pessoas trans tem 49 vezes mais chances de contrair o vírus do HIV/AIDS que o total da população adulta no geral. Não há dados exatos no Brasil sobre trans portadores de HIV, mas estima-se que a realidade não seja diferente da apresentada a nível mundial (MOTT, 2014; UNAIDS, 2015).

Quando se trata de invisibilidade trans, pode ser usada uma reflexão muito interessante de Jurema Werneck em seu discurso sobre aniquilamento de mulheres negras (2013): quando levada para a esfera da violência, há uma necessidade do apagamento de uma figura ou imagem, de algo que não deve aparecer, não pode ser dita ou representada. Logo, Werneck afirma que invisibilidade não é estado de ausência e nem desaparecimento, mas sim, de uma existência contraditória, indesejada e desafiadora, mas que precisa ser abafada e retirada do meio social através de discursos e atitudes patriarcais e heteronormativos, chamando essa figura de ausência, mas que estão presentes e notáveis na sociedade, daí surge a necessidade de aniquilar.

No que tange a realidade violenta que pessoas trans são expostas, não só no Brasil, mas a nível mundial, a Organização das Nações Unidas vem demonstrando intensa preocupação com esta população e faz apelos constantemente aos Estados membros para atentarem para suas realidades internas, a fim de proteger os LGBTTT e endurecer leis 
punitivas para crimes motivados pelo ódio. E é aí que o doméstico interage com o internacional, quando os países membros seguem os mesmos princípios universais para lidar com orientação sexual e identidade de gênero, os Princípios de Yogyakarta, que é a Lei Internacional de Direitos Humanos em relação à Orientação Sexual e Identidade de Gênero, considerada como o princípio mais relevante no âmbito do Direito Internacional. O direito democrático à livre sexualidade, não é um assunto novo. Esta reflexão parte de dois pilares fundamentais que são referenciais no regime internacional de direitos humanos: igualdade e não discriminação. Desta forma, podemos afirmar que não há possibilidades de outras interpretações da Declaração Universal dos Direitos dos Humanos que, começa seu texto com a seguinte afirmativa: "todos os seres humanos nascem livres e iguais em dignidade e direitos."

De acordo com a Alta Comissária da ONU, Navy Pillay (2013), os Estados têm obrigações junto ao direito internacional a fim de investigar tais violações e levar os responsáveis à justiça. A Assembleia Geral das Nações Unidas recomendou aos Estados que "(...) garantissem a proteção do direito à vida de todas as pessoas sob sua jurisdição" e investigassem de forma rápida e comprometida com tais violações, inclusive, as que foram motivadas pela orientação sexual e identidade de gênero da vítima. Assim sendo, se um Estado deixar de investigar e punir um crime, estará violando também suas obrigações perante a lei internacional (PILLAY, 2013).

O atual momento de conformação da Agenda 2030 (a nova agenda global da ONU que foi aprovada no dia 27 de setembro de 2015) para o Desenvolvimento Sustentável, revela-se oportuno para o Brasil identificar ações e estratégias eficazes, que promovam, de fato, a garantia do Direito à liberdade e à livre sexualidade, a fim de contribuir para o item 16.1 do Objetivo de Desenvolvimento Sustentável relacionado à redução de todas as formas de violência bem como as taxas de mortalidade em todos os lugares, o que inclui as violações e privações à vida em razão da identidade de gênero e orientação sexual (ONU, 2015).

Na realidade, as características "progressistas" da constituição brasileira nesse campo, principalmente, seu engajamento na luta pela prevenção ao HIV (AIDS), foram amplamente reconhecidos e exaltados. Pode-se dizer que, o país teve grandes progressos no que diz respeito aos direitos sexuais, porém, atualmente, é arena de grandes batalhas político-religiosas que mantém e até mesmo, intensificam uma concepção patriarcal por parte da sociedade civil e da crescente influência da bancada religiosa, sobre o que um dia ativistas LGBTTT e feministas lutaram arduamente para conquistar. A política sexual vigente hoje, no Brasil, é representada por uma 'subserviência' ímpar do Governo Federal aos grupos conservadores e consequentemente, conserva e aumenta, a manutenção da mentalidade social heteronormativa e preconceituosa (CORRÊA, 2013).

Esses retrocessos frente a diversidade sexual não deveriam enfraquecer a luta, que trazem em suas realidades os problemas que decorrem da configuração da presença cada vez mais atenuante dos Estados e do conservadorismo nas políticas de gênero, sexualidade e "raça". Há de se enxergar que o contexto atual assiste a voltade de antigas e novas lógicas soberanistas e heteronormativas. É por este motivo, que mais do que nunca, talvez, tenha sido tão importante para a sociedade civil persistir na luta para dar continuidade ao trabalho árduo de desenvolvimento dos direitos à livre sexualidade que foi severamente conquistado 
e não deve de maneira alguma sofrer repressão em seu exercício.

\section{BIBLIOGRAFIA}

BEAUVOIR, Simone. O segundo sexo: A experiência vivida, $2^{\mathrm{a}}$ ed. Trad. Sérgio Milliet. Rio de Janeiro, RJ: Nova Fronteira, vol. 2, 1980.

BENTO, Berenice. Brasil: O país do transfeminicídio. CLAM, Rio de Janeiro, 2014.

BUTLER, Judith. Problemas de Gênero: feminismo e subversão da identidade; Trad. Renato Aguiar. $-2^{\circ}$ ed. - Rio de Janeiro: civilização Brasileira, 2008.

CARRARA, Sérgio; VIANNA, Adriana R.B. Tá lá o corpo estendido no chão: a Violência Letal contra Travestis no Município do Rio de Janeiro. Disponível em: http://www.scielo.br/pdf/physis/v16n2/v16n2a06.pdf. Acesso em: 09/09/2015.

CORRÊA, Sônia. "Sexualidade e política da segunda década dos anos 2000: O curso longo e as armadilhas do presente". In: Feminilidades: Corpos e sexualidades em debate. Rio de Janeiro, EdUERJ, 2013.

MOTT, luiz. Grupo Gay da Bahia. In: Assassinatos de homossexuais (LGBT) no Brasil: relatório 2014. Bahia, 2014.

ONU. Transformando Nosso Mundo: A Agenda 2030 para o Desenvolvimento Sustentável. https://sustainabledevelopment.un.org. Acesso em: 10/09/2015.

PILLAY, Navy. Nascidos Livres e Iguais: Orientação Sexual e Identidade de Gênero no regime Internacional de Direitos Humanos. Nações Unidas. Brasília, 2013.

Princípios de Yogyakarta. Princípios sobre a aplicação da legislação internacional de direitos humanos em relação à orientação sexual e identidade de gênero. Genebra, 2007.

UNAIDS. GLOBAL AIDS RESPONSE PROGRESS REPORTING, Switzerland, 2015. WERNECK, Jurema. "É preciso imagem para recuperar a identidade": história de nós, mulheres negras e processos de aniquilamento. In: Feminilidades: corpos e sexualidades em debate. Rio de Janeiro, EdUERJ, 2013. 